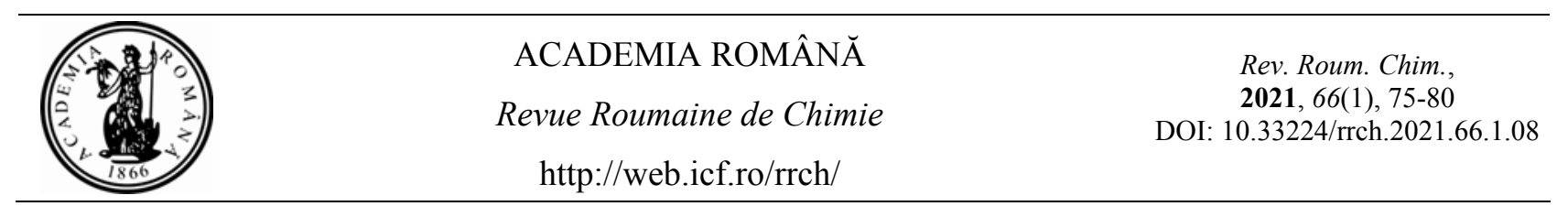

\title{
QUINIZARIN INTERACTION WITH BILE SALTS MICELLES AS BIOMIMETIC MODEL MEMBRANES
}

\author{
Ana Maria TOADER and Mirela ENACHE ${ }^{*}$ \\ Institute of Physical Chemistry Ilie Murgulescu, Roumanian Academy, Splaiul Independentei 202, Bucharest 060021, Roumania
}

The evaluation of the interaction of quinizarin (Q), an analogue of the core unit of various anticancer drugs, with two bile salts sodium cholate $(\mathrm{NaC})$ and sodium deoxycholate $(\mathrm{NaDC})$ in $0.1 \mathrm{M}$ phosphate buffer $(\mathrm{pH}$ 7.4), investigated by absorption and conductance measurements is presented in this work. The values of binding constant $\left(\mathrm{K}_{\mathrm{b}}\right)$, partition coefficient $\left(\mathrm{K}_{\mathrm{x}}\right)$ and free energy change $(\Delta \mathrm{G})$ were determined and discussed in terms of possible intermolecular interactions. The results indicate higher binding constant and partition coefficient values for $\mathrm{NaDC}$ micelles than $\mathrm{NaC}$ micelles and this distinct interaction of quinizarin with $\mathrm{NaTDC}$ and $\mathrm{NaTC}$ micelles is supported by the differences in nature and structure of bile salts micelles. The critical micelle concentration (CMC) of both bile salts, determined using electrical conductivity measurements is higher in the presence of quinizarin.

\section{INTRODUCTION}

Anthracycline drugs are chemotherapeutic agents containing a planar hydroxy-9,10-anthraquinone chromophore substituted with an amino sugar. They are used in the treatment of a broad range of human cancers because of their effectiveness to destroy malignant tumor cells. One of the mechanisms responsible for antitumor activity of these drugs is the intercalation of the aromatic moiety between the DNA base pairs, resulting in the inhibition of both DNA replication and RNA transcription. ${ }^{1-4}$ To reach the target DNA in the cell nucleus and to obtain the desired pharmacological activity, the drug molecules must cross the cell membrane as well the nuclear envelope. Therefore, the biological membranes are the first barrier encountered by drug molecules and the understanding of the interaction

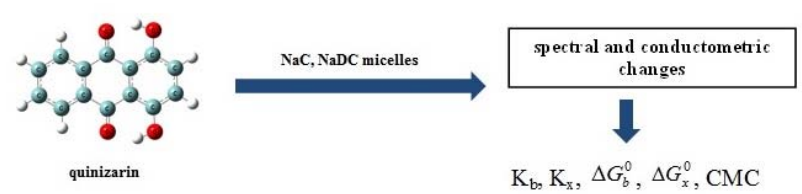

$\mathrm{K}_{\mathrm{b}}, \mathrm{K}_{\mathrm{x}}, \Delta G_{b}^{0}, \Delta G_{x}^{0}, \mathrm{CMC}$

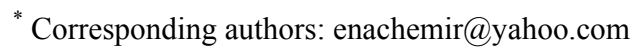

between them is essential because these interactions are related with drug transport, accumulation and biological activity. ${ }^{5}$ Biological membranes represent very complex structures making difficult investigation of interaction with biological active compounds. To overcome this difficulty, micelles with their hydrophobic core and hydrophilic outer layer are used as simple biomimetic models in order to study the interactions between drug molecules and membranes. ${ }^{6-11}$ Besides, the surfactant micelles are widely used as drug delivery vehicles in pharmaceutical biotechnology. The surfactant micelles increase the solubility of hydrophobic drugs, help in minimization of the drug degradation and increase the bioavailability of drugs. ${ }^{12-14}$

As the planar anthraquinone unit of anthracycline drugs is responsible for both DNA binding and cardiac toxicity of these molecules, different 
simpler and less expensive anthraquinones have been studied and compared with the known drugs. ${ }^{11,15-18}$

Quinizarin (1,4-dihydroxy-9,10-anthraquinone, Q) is a member of the synthetic anthraquinones class which are known for their antibacterial, antifungal and antioxidant properties. ${ }^{19,20}$ Also, quinizarin is the simplest molecule showing the chromophore framework typical to several antitumor drugs as doxorubicin, daunorubicin, aclacinomycin or mitoxantrone. The anthraquinone chromophore is responsible for the affinity of these drugs toward DNA and also is involved in generation of reactive oxygen species responsible for the cardiotoxicity of these drugs. ${ }^{21,22}$ Besides, quinizarine is generally used as fuel marker to distinguish the origin and quality of fuels. ${ }^{23}$

Sodium cholate $(\mathrm{NaC})$ and sodium deoxycholate (NaDC) belongs to bile salts which are steroid anionic amphiphiles, which form micelles above the critical micelle concentration (CMC). Micelles of bile salts play an important role in drug delivery and their solubilization process. ${ }^{24-27}$ Bile salts have a very different structure in comparison with conventional surfactants. Bile salts present a large, rigid and planar hydrophobic steroid moiety with attached two or three hydroxyl groups and an anionic carboxyl head group. Thus, bile salts have a facial structure with a hydrophobic surface and a hydrophilic surface or, depending on the position and orientation of the hydroxyl groups, a hydrophilic edge only. The hydrophobic and hydrophilic domains are not clearly separated as in classical micelles. ${ }^{28}$ The presence of different binding sites makes bile salt micelles able to carry both hydrophilic and hydrophobic drug molecules depending on the structure and size of the molecules. ${ }^{29-32}$

The aim of the present work was to investigate the interaction of quinizarin with micelles formed by the anionic bile salts, sodium cholate $(\mathrm{NaC})$ and sodium deoxycholate $(\mathrm{NaDC})$ as simple model system for biological membranes. The reason for use of quinizarin in these studies was the presence of planar 9,10-anthraquinone unit playing a key role in pharmacological activity of different anticancer drugs. The interaction of quinizarin with $\mathrm{NaC}$ and NaDC micelles was studied by employing absorption and conductometric techniques. The binding constant, partition coefficient and thermodynamic parameters for both binding and partition processes were calculated and discussed in comparison with our previous results. $\mathrm{NaC}$ and $\mathrm{NaDC}$ have the same head group $\left(-\mathrm{CH}_{2}-\mathrm{CH}_{2}-\mathrm{CO}_{2}^{-}\right)$but $\mathrm{NaC}$ contains three hydroxyl groups in the hydrophilic surface as against $\mathrm{NaDC}$ which contains only two hydroxyl groups. The hydroxyl groups make $\mathrm{NaC}$ less hydrophobic as compared to NaDC.

\section{EXPERIMENTAL}

Quinizarin (96\% purity), $\mathrm{NaC}, \mathrm{NaDC}$ and other chemicals were purchased from Sigma Aldrich and were used without any purification. Experiments were performed in $0.1 \mathrm{M}$ phosphate buffer ( $\mathrm{pH}$ 7.4). A concentrated stock solution of quinizarin $(2 \mathrm{mM})$ was prepared by dissolving suitable amount of quinizarin in methanol. Small aliquots of quinizarin stock solution were diluted with phosphate buffer and used in different experiments.

Spectrophotometric measurements were made on a JASCO V-630 spectrophotometer equipped with a Peltiercontrolled ETCR-762 model accessory (JASCO Corporation, Tokyo, Japan). The absorption spectra of quinizarin alone and in the presence of different concentrations of bile salts were recorded in the wavelength range of $350-700 \mathrm{~nm}$ and 293,15 K temperature.

Specific conductivities were measured with Consort K912 conductivity meter (Parklaan 36, B-2300 Turnhout, Belgium) which has auto ranging from 0 to $1000 \mathrm{mS} / \mathrm{cm}$. The electrode used has a cell constant of $0.98 \mathrm{~cm}^{-1}$. The conductivity experiments were performed as follows: small volume of concentrated solution of bile salts were added gradually into $0.1 \mathrm{M}$ phosphate buffer ( $\mathrm{pH} 7.4)$, in the absence and in the presence of quinizarin. The specific conductivity values were recorded after each addition of the stock solution.

\section{RESULTS AND DISCUSSION}

\section{UV-Vis absorption studies}

The visible absorption spectra of quinizarin in the absence and in the presence of of $\mathrm{NaC}$ and $\mathrm{NaDC}$ in $0.1 \mathrm{M}$ phosphate buffer $(\mathrm{pH} 7.4)$ in the concentration range of $4.25 \times 10^{-3} \mathrm{M}-7.18 \times 10^{-2} \mathrm{M}$ for $\mathrm{NaC}$ and $2.50 \times 10^{-3} \mathrm{M}-1.10 \times 10^{-2} \mathrm{M}$ for $\mathrm{NaDC}$ are shown in Fig. 1. At neutral $\mathrm{pH}$, the visible absorption spectrum of quinizarin shows a broad absorption maximum at $\sim 470 \mathrm{~nm}$ and a shoulder at about $535 \mathrm{~nm}$. The presence of increasing $\mathrm{NaC}$ and $\mathrm{NaDC}$ concentrations leads to an increase of the absorption maximum of quinizarin. Also, it was observed that increasing bile salts concentrations the shoulder around $520 \mathrm{~nm}$ is resolved showing two new peaks $(518 \mathrm{~nm}$ and 503 $\mathrm{nm}$ for $\mathrm{NaC}$ and $520 \mathrm{~nm}$ and $507 \mathrm{~nm}$ for $\mathrm{NaDC}$, respectively) and the shoulder at about $535 \mathrm{~nm}$ disappears. These spectral changes prove the interaction between quinizarin and $\mathrm{NaC}$ and $\mathrm{NaDC}$ micelles and the gradual incorporation of quinizarin molecule into micelles. Also, the environment around quinizarin molecule in micelles is different form bulk aqueous solution as the absorption maximum is shifted towards longer wavelengths (about $18 \mathrm{~nm}$ ). 

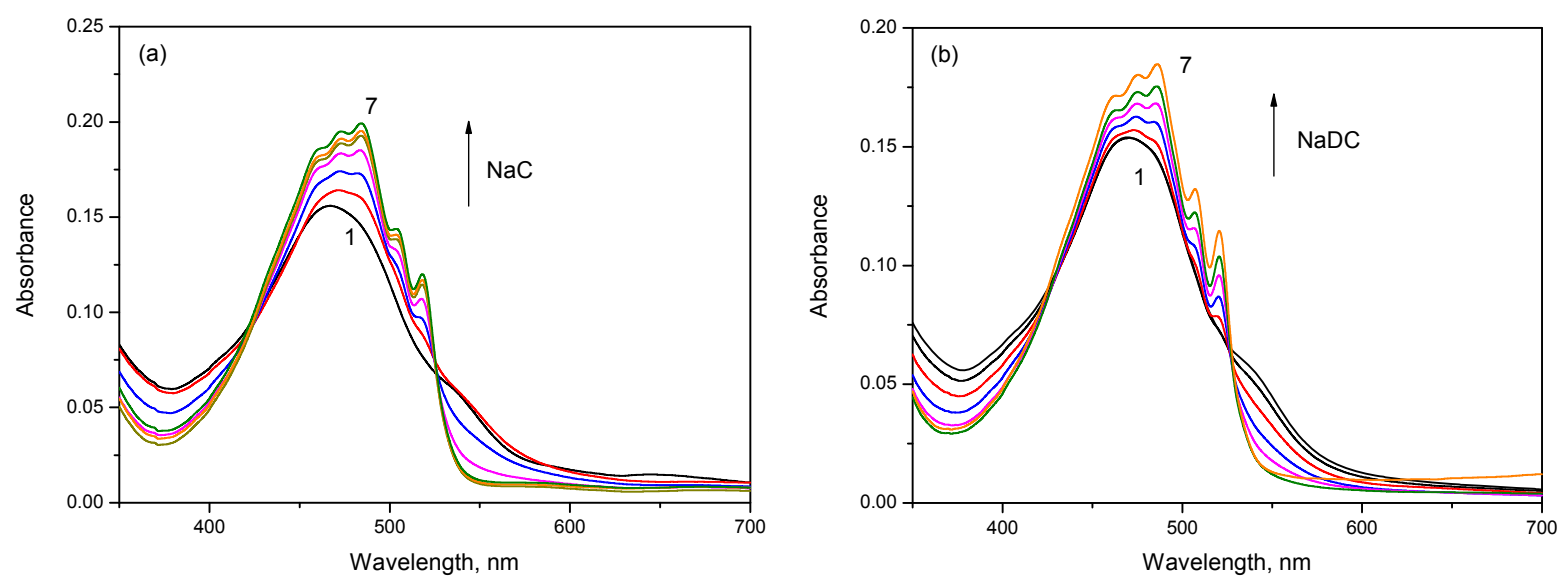

Fig. 1 - Absorption spectra of $1.80 \times 10^{-5} \mathrm{M}$ quinizarin in $0.1 \mathrm{M}$ phosphate buffer ( $\mathrm{pH} 7.4$ ) in the absence (spectrum 1) and in the presence of increasing amounts of $\mathrm{NaC} \mathrm{(a)} \mathrm{and} \mathrm{NaDC}(\mathrm{b})$.
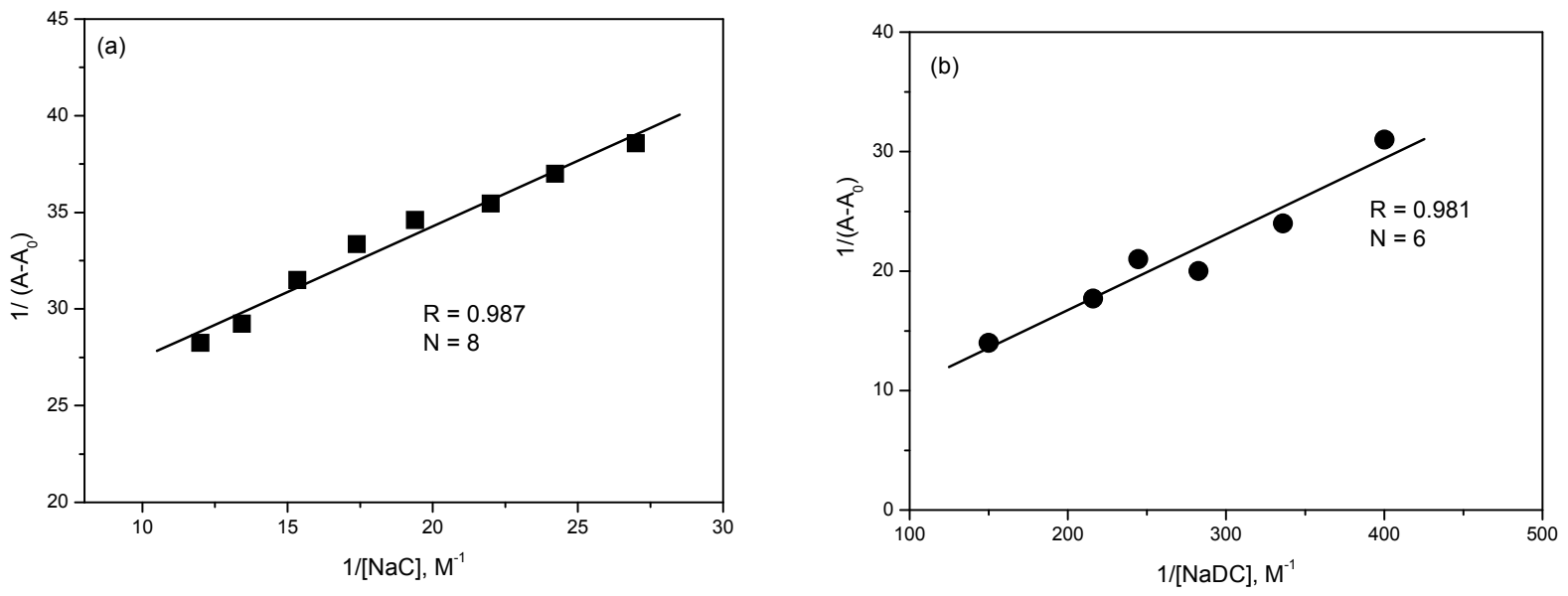

Fig. 2 - Plot of $1 /\left(\mathrm{A}-\mathrm{A}_{0}\right)$ versus $1 /[$ micelles] for the interaction of quinizarin with NaC micelles (a) and NaDC micelles (b).

\section{Determination of binding constant $\left(K_{b}\right)$ and partition coefficient $\left(K_{x}\right)$}

The changes in the absorption spectra of quinizarin in the presence of increasing bile salts concentrations were used to determine the quinizarin-bile salts micelles binding constant $\left(\mathrm{K}_{\mathrm{b}}\right)$ and the partition coefficient $\left(\mathrm{K}_{\mathrm{x}}\right)$ of quinizarin between aqueous and micelles phases.

The binding constants of quinizarin to $\mathrm{NaC}$ and $\mathrm{NaDC}$ micelles were estimated from the BenesiHildebrand equation: $:^{33,34}$

$$
\frac{1}{\mathrm{~A}-\mathrm{A}_{0}}=\frac{1}{\mathrm{~K}_{\mathrm{b}}\left(\mathrm{A}_{1}-\mathrm{A}_{0}\right)[\text { micelles }]}+\frac{1}{\mathrm{~A}_{1}-\mathrm{A}_{0}}
$$

where [micelles] is the concentration of micellized $\mathrm{NaC}$ or $\mathrm{NaDC}, \mathrm{A}$ and $\mathrm{A}_{0}$ are the values of absorbance of drug in the presence and absence of micelles respectively, and $\mathrm{A}_{1}$ is the absorbance due to the formation of drug-micelles complex. The plot of $1 /\left(\mathrm{A}-\mathrm{A}_{0}\right)$ vs. $1 /$ [micelles] gives straight lines for both types of micelles (Fig. 2), indicating the formation of a 1:1 complex between quinizarin and $\mathrm{NaC}$ and $\mathrm{NaDC}$ micelles. The values of the binding constant obtained from the ratio of the intercept to slope of the Benesi-Hildebrand plots are given in Table 1.

It can be observed that the binding constant has small values for the interaction of quinizarin with both bile salts. A stronger interaction is noticed in the case of $\mathrm{NaDC}$ micelles $\left(68 \mathrm{M}^{-1}\right.$ for $\mathrm{NaDC}$ micelles as against $29 \mathrm{M}^{-1}$ for $\mathrm{NaC}$ micelles). This result can be justified taking into account the difference in the hydrophobicity of micelles core of the two bile salts. $\mathrm{NaDC}$ and $\mathrm{NaC}$ have the same head group but $\mathrm{NaC}$ presents an additional hydroxyl group leading to a more hydrophilic surface of $\mathrm{NaC}$ than in the case of $\mathrm{NaDC}$. This remark implies that the hydrophobic interactions between quinizarin and $\mathrm{NaDC}$ micelles are much stronger compared to that between quinizarin and $\mathrm{NaC}$ micelles. The binding constants for the 
quinizarin interaction with both bile salts micelles are much smaller than the binding constant for the interaction of quinizarin with SDS micelles (2524 $\left.\mathrm{M}^{-1}\right){ }^{35}$ probable due to the very different structures between SDS and bile salts micelles. Comparing the value of the binding constant for the interaction of quinizarin with $\mathrm{NaC}$ micelles with that for the interaction of mitoxantrone with $\mathrm{NaC}$ micelles $\left(4360 \mathrm{M}^{-1}\right),{ }^{27}$ we observe that the interaction of mitoxantrone with $\mathrm{NaC}$ micelles is stronger than the interaction of quinizarin with $\mathrm{NaC}$ micelles. At $\mathrm{pH}$ 7.4, mitoxantrone has two positive charges while quinizarin is uncharged, therefore in the case of mitoxantrone the electrostatic interactions between positive charges of mitoxantrone and anionic $\mathrm{NaC}$ micelles in addition to hydrophobic interactions can explain the stronger interaction between mitoxantrone and $\mathrm{NaC}$ micelles.

Partition coefficient $\left(\mathrm{K}_{\mathrm{x}}\right)$ was evaluated from the following equation, according to the pseudophase model: ${ }^{36}$

$$
\frac{1}{\Delta \mathrm{A}}=\frac{1}{\Delta \mathrm{A}_{\infty}}+\frac{\mathrm{n}_{\mathrm{W}}}{\mathrm{K}_{\mathrm{x}} \Delta \mathrm{A}_{\infty}\left([\text { micelles }]+\mathrm{C}_{\mathrm{T}}-\mathrm{CMC}\right)}
$$

where $\Delta \mathrm{A}=\mathrm{A}-\mathrm{A}_{0}, \Delta \mathrm{A}_{\infty}=\mathrm{A}_{1}-\mathrm{A}_{0}, \mathrm{C}_{\mathrm{T}}$ is the total quinizarin concentration and $n_{\mathrm{w}}=55.5 \mathrm{M}$ is the molarity of water. The value of $\mathrm{K}_{\mathrm{x}}$ is obtained from the slope of the plot of $1 / \Delta \mathrm{A}$ versus $1 /\left(\mathrm{C}_{\mathrm{T}}+\right.$ [micelles] - CMC) as shown in Fig. 3.

The analysis of the results from Table 1 indicates that quinizarin shows high partition coefficients for both bile salt micelles but higher for $\mathrm{NaDC}$ comparing to $\mathrm{NaC}$. Consequently, we can say that quinizarin molecules are entrapped more efficiently in $\mathrm{NaDC}$ micelles and this difference can be explained by the higher micelles formed by dihydroxy bile salts $(\mathrm{NaDC})$ as against trihydroxy bile salts $(\mathrm{NaC}){ }^{37}$ Also, spin-label studies performed by Kawamura et al. ${ }^{38}$ showed differences in the micellar structures between dihydroxy bile salts and trihydroxy bile salts in spite of their similar shapes. Compared with SDS micelles, the partition coefficients of quinizarin into $\mathrm{NaC}$ and $\mathrm{NaDC}$ micelles are smaller than the partition coefficient of quinizarin into SDS micelles. ${ }^{35}$ This can be explained by the smaller size of bile salt micelles (the micellar radius for $\mathrm{NaC}$ and $\mathrm{NaDC}$ micelles is $10.8 \AA$, respectively 9$12 \AA)^{39,40}$ compared with SDS micelles (the micellar radius $19.4 \AA),{ }^{41}$ although their molecular length is almost the same. ${ }^{42}$

Table 1

Binding constant $\left(\mathrm{K}_{\mathrm{b}}\right)$, partition coefficient $\left(\mathrm{K}_{\mathrm{x}}\right)$ and the Gibbs free energy for the binding $\left(\Delta G_{b}^{0}\right)$ and the transfer of quinizarin from bulk water to micellar phase $\left(\Delta G_{x}^{0}\right)$ for the interaction of quinizarin with $\mathrm{NaC}$ and $\mathrm{NaDC}$ micelles

\begin{tabular}{c|c|c|c|c}
\hline & $\mathrm{K}_{\mathrm{b}}, \mathrm{M}^{-1}$ & $\Delta G_{b}^{0}, \mathrm{~kJ} / \mathrm{mol}$ & $\mathrm{K}_{\mathrm{x}}$ & $\Delta G_{x}^{0}, \mathrm{~kJ} / \mathrm{mol}$ \\
\hline $\mathrm{NaC}+\mathrm{Q}$ & $29 \pm 5$ & -8.20 & $5587 \pm 125$ & -21.02 \\
$\mathrm{NaDC}+\mathrm{Q}$ & $68 \pm 8$ & -10.28 & $62530 \pm 3547$ & -26.90 \\
\hline
\end{tabular}
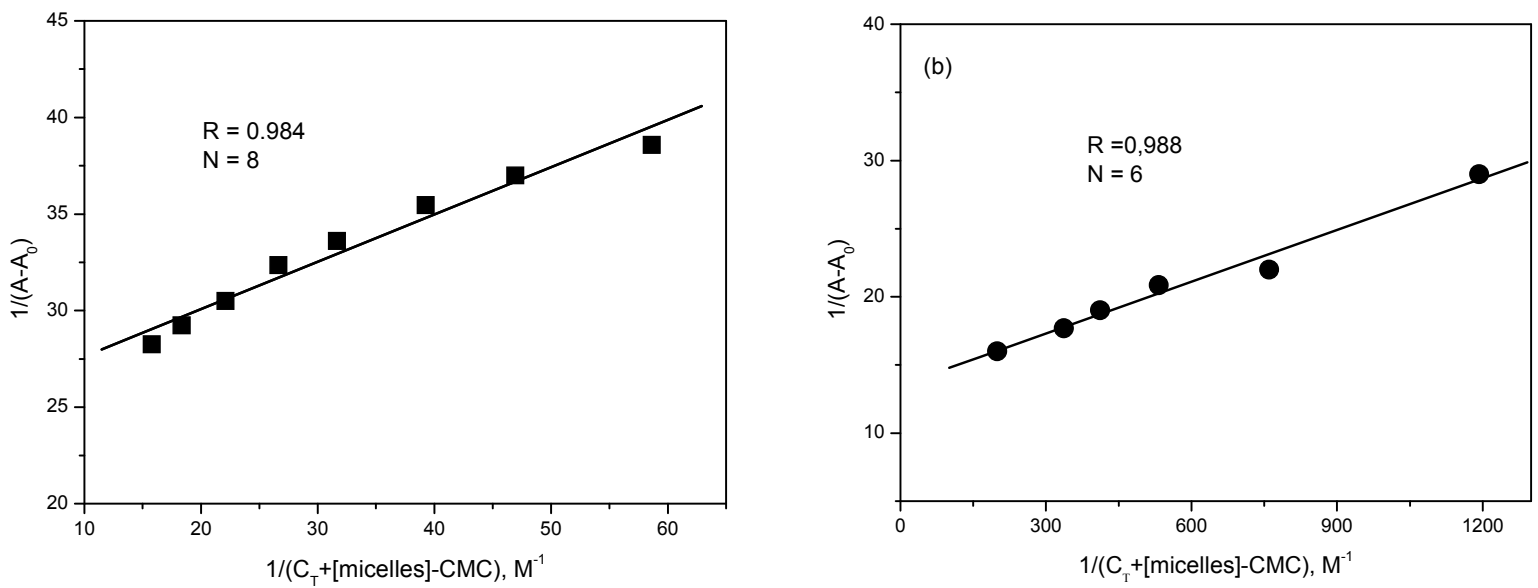

Fig. 3 - Plot of $1 /\left(A-A_{0}\right)$ versus $1 /\left(C_{T}+\right.$ [micelles]-CMC) for the interaction of quinizarin with $\mathrm{NaC}$ micelles (a) and $\mathrm{NaDC}$ micelles (b). 

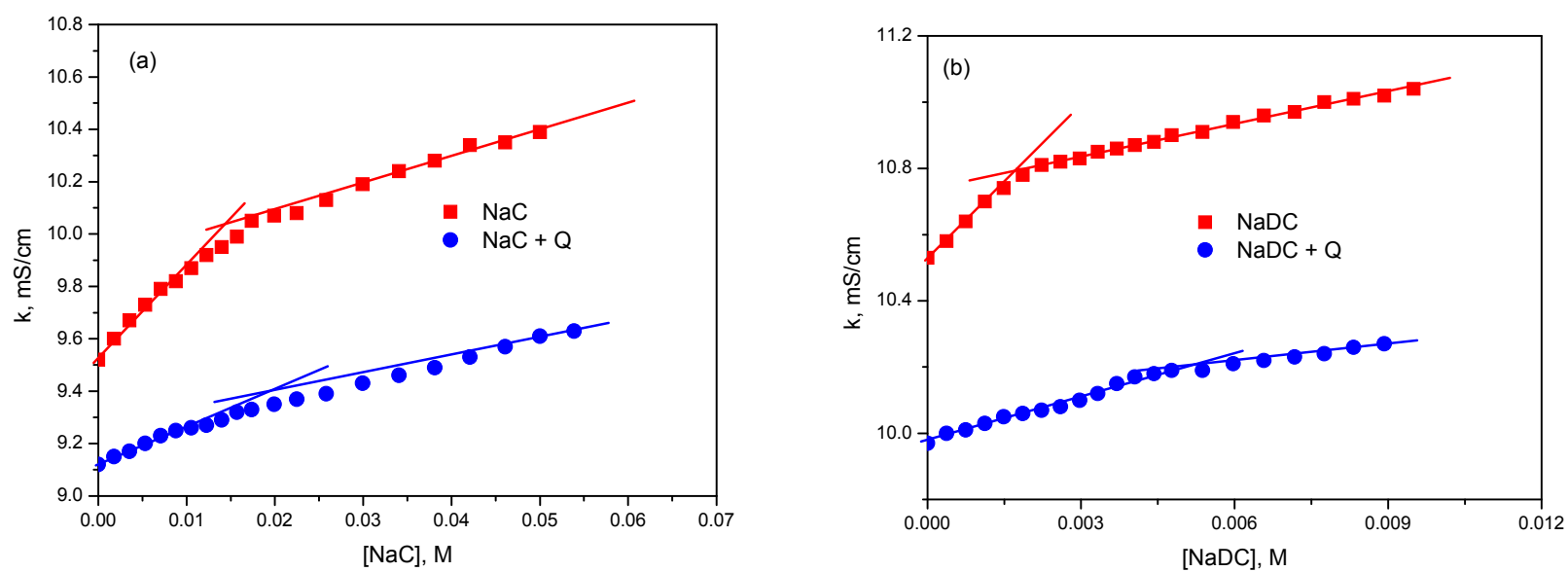

Fig. 4 - Specific conductivity $(\kappa)$ as a function of $\mathrm{NaC}(\mathrm{a})$ and $\mathrm{NaDC}(\mathrm{b})$ concentration in the absence and the presence of quinizarin in $0.1 \mathrm{M}$ phosphate buffer $\mathrm{pH}$ 7.4.

Table 2

Critical micelle concentration (CMC), degree of ionization $(\alpha)$ and degree of counterion binding ( $\beta$ ) for $\mathrm{NaC}$ and $\mathrm{NaDC}$ in $0.1 \mathrm{M}$ phosphate buffer ( $\mathrm{pH} 7.4)$ in the absence and the presence of $2.15 \times 10^{-5} \mathrm{M}$ quinizarin

\begin{tabular}{c|c|c|c}
\hline & CMC, M & $\alpha$ & $\beta$ \\
\hline $\mathrm{NaC}$ & $1.46 \times 10^{-2}$ & $0.35 \pm 0.018$ & $0.65 \pm 0.018$ \\
$\mathrm{NaC}+\mathrm{Q}$ & $1.98 \times 10^{-2}$ & $0.61 \pm 0.024$ & $0.39 \pm 0.022$ \\
$\mathrm{NaDC}$ & $1.68 \times 10^{-3}$ & $0.24 \pm 0.019$ & $0.76 \pm 0.031$ \\
$\mathrm{NaDC}+\mathrm{Q}$ & $5.23 \times 10^{-3}$ & $0.48 \pm 0.026$ & $0.52 \pm 0.026$ \\
\hline
\end{tabular}

From the values of $\mathrm{K}_{\mathrm{b}}$ and $\mathrm{K}_{\mathrm{x}}$, the Gibbs free energy of interaction $\left(\Delta G_{b}^{0}\right)$ and the Gibbs free energy of the transfer of drug from bulk aqueous phase to micellar phase $\left(\Delta G_{x}^{0}\right)$ were determined employing the relation:

$$
\Delta \mathrm{G}^{0}=-\mathrm{RT} \ln \mathrm{K}
$$

The negative values of $\Delta \mathrm{G}$ for both binding and partitioning processes show that the binding of quinizarin to $\mathrm{NaC}$ and $\mathrm{NaDC}$ micelles is energetically favorable.

\section{Conductometric studies}

The electrical conductivity measurement is a reliable and sensitive method to determine the critical micellar concentration (CMC). The variation of conductivity $(\kappa)$ with surfactant concentration is depicted in Fig. 4. It can be observed that two straight lines with different slopes are obtained and the intersection point of both straight lines gives the $\mathrm{CMC}$.

The $\mathrm{CMC}$ values of pure $\mathrm{NaC}$ and $\mathrm{NaDC}$ were found to be similar with those reported in the literature. ${ }^{43}$ In the presence of quinizarin, the CMC of both bile salts increases. The increase of the CMC of different surfactants was also observed for other drugs or dyes and it was attributed to hydrogen bonds formation between hydrophilic groups of drug (dye) and water leading to the solubilization of drug (dye) in outer portion of micelle close to micelle water interface. Thus, the entropy decreases and the micellization process is less favorable and the CMC increases. ${ }^{44,45}$

The degree of ionization $(\alpha)$ of the micelles can be estimated from the ratio of the slopes of the two straight lines corresponding to above and below CMC, when the specific conductivity is plotted versus concentration. The degree of counterion association $(\beta)$ is given as $\beta=1-\alpha{ }^{46}$ It can be seen that the presence of quinizarin leads to an increase of the degree of ionization for both bile salts.

\section{CONCLUSIONS}

The interaction of quinizarin, a simple molecule showing the chromophore specific to several anticancer drugs with micelles formed by the anionic bile salts, sodium cholate $(\mathrm{NaC})$ and sodium deoxycholate $(\mathrm{NaDC})$ was investigated by absorption and conductometric techniques. The values of binding constants indicate a stronger interaction of quinizarin with $\mathrm{NaDC}$ micelles than with $\mathrm{NaC}$ micelles. Also, quinizarin molecules are entrapped more efficiently in $\mathrm{NaDC}$ micelles than 
in $\mathrm{NaC}$ micelles as indicated by the values of partition coefficients. These differences can be explained by the difference in the hydrophobicity of micelles core of the two bile salts and by the higher micelles formed by dihydroxy bile salts $(\mathrm{NaDC})$ as against trihydroxy bile salts $(\mathrm{NaC})$. The present results can contribute to the general understanding of the drug-biomembranes interaction and eventually for the design of more efficient drug delivery systems.

\section{REFERENCES}

1. S. Agarwal, D. K. Jangir and R. Mehrotra, J. Photochem. Photobiol. B, 2013, 120, 177-182.

2. D. Agudelo, P. Bourassa, G. Bérubé and H. A. TajmirRiahi, J. Photochem. Photobiol. B, 2016, 158, 274-279.

3. M. Enache and E. Volanschi, Rev. Roum. Chim., 2005, 50, 131-140.

4. Z. Hajihassan and A. Rabbani-Chadegani, Int. J. Biol. Macromol., 2011, 48, 87-92.

5. C. Bourgaux and P. Couvreur, J. Control Release, 2014, 190, 127-138.

6. T. S. Banipal, R. Kaur and P. K. Banipal, J. Mol. Liq., 2018, 255, 113-121.

7. A. D. Saraf and S. Sharma, S. Sachar, Langmuir, 2018, 34, 14624-14632.

8. M. Enache, A. M. Toader and M. I. Enache, Molecules, 2016, 21, 1356, 1-17.

9. M. Enache, S. Ionescu and E. Volanschi, J. Mol. Liq., 2015, 208, 333-341.

10. M. Enache and A. M. Toader, J. Surfactants Deterg., 2018, 21, 31-41.

11. A. Das, S. Roy, P. Mondal, A. Datta, K. Mahali, G. Loganathan, D. Dharumadurai, P. S. Sengupta, M. A. Akbarsha and P. S. Guin, RSC Adv., 2016, 6, 28200 28212.

12. A. Mukhija and N. Kishore, J. Mol. Liq., 2018, 265, 1-15.

13. M. N. Alizadeh, A. Shayanfar and A. Jouyban, J. Mol. Liq., 2018, 268, 410-414.

14. T. Farias, L. C. de Menorval, J. Zajac and A. Rivera, Colloids Surf. A Physicochem. Eng. Asp., 2009, 345, 51-57.

15. P. Mondal, S. Roy, G. Loganathan, B. Mandal, D. Dharumadurai, M. A. Akbarsha, P. S. Sengupta, S. Chattopadhyay and P. S. Guin, Biochem. Biophys. Rep., 2015, 4, 312-323.

16. P. S. Guin, S. Das and P. C. Mandal, J. Solution. Chem., 2011, 40, 492-501.

17. M. B. Gholivand, S. Kashanian, H. Peyman and H. Roshanfekr, Eur. J. Med. Chem., 2011, 46, 2630-2638.

18. V. Verebova, J. Adamcik, P. Danko, D. Podhradsky, P. Miskovsky and J. Stanicova, Biochem. Biophys. Res. Commun., 2014, 444, 50-55.

19. G. Zengin, N. S. Degirmenci, L. Alpsoy and A. Aktumsek, Hum. Exp. Toxicol., 2016, 35, 544-553.
20. S. Rossi, C. Tabolacci, A. Lentini, B. Provenzano, F. Carlomosti, S. Frezzotti and S. Beninati, Anticancer Res., 2010, 30, 445-449.

21. C. Batchelor-Mcauley, I. B. Dimov, L. Aldous and R. G. Compton, Proc. Natl. Acad. Sci. USA, 2011, 108, 19891-19895.

22. T. Simunek, M. Sterba, O. Popelova, M. Adamcova, R. Hrdina and V. Gersl, Pharmacol. Rep., 2009, 61, 154171.

23. M. A. G. Trindade, U. Bilibio and M. V. B. Zanoni, Fuel, 2014, 136, 201-207.

24. N. A. Malik, Appl. Biochem. Biotechnol., 2016, 179, 179-201.

25. T. Yadav, D. Tikariha, S. Sinha and K. K. Ghosh, J. Mol. Liq., 2017, 233, 23-28.

26. S. Mahajan, R. K. Mahajan, J. Colloid Interface Sci., 2012, 387, 194-204.

27. M. Enache and A. M. Toader, Rev. Chim. (Bucharest), 2018, 69, 1060-1065.

28. D. Madenci and S.U. Egelhaaf, Curr. Opin. Colloid Interface Sci., 2010, 15, 109-115.

29. S. Mandal, S. Ghosh, C. Banerjee, V. G. Rao and N. Sarkar, J. Phys. Chem. B, 2012, 116, 8780-8792.

30. S. Sen, B. K. Paul and N. Guchhait, J. Colloid Interface Sci., 2017, 505, 266-277.

31. R. Thakur, A. Das, C. Adhikari and A. Chakraborty, Phys. Chem. Chem. Phys., 2012, 14, 15369-15378.

32. S. Mandal, S. Ghosh, D. Banik, C. Banerjee, J. Kuchlyan and N. Sarkar, J. Phys. Chem. B, 2013, 117, 1379513807.

33. H. A. Benesi and J. H. Hildebrand, J. Am. Chem. Soc., 1949, 71, 2703-2707.

34. Y. Shiraishi, S. Sumiya, Y. Kohno and T. Hirai, J. Org. Chem., 2008, 73, 8571-8574.

35. A. M. Toader, P. Oancea and M. Enache, Acta Chim. Slov., 2020, 67, 629-637.

36. H. Kawamura, M. Manabe, Y. Miyamoto, Y. Fujita and S. Tokunaga, J. Phys. Chem., 1989, 93, 5536-5540.

37. N. A. Mazer, M. C. Carey, R. F. Kwasnick and G. B. Benedek, Biochemistry, 1979, 18, 3064-3075.

38. H. Kawamura, Y. Murata, T. Yamaguchi, H. Igimi, M. Tanaka, G. Sugihara and J. P. Kratohvil, J. Phys. Chem., 1989, 93, 3321-3326.

39. V. A. Maslovaa and M. A. Kiseleva, Crystallogr. Rep., 2018, 63, 472-475.

40. G. Esposito, E. Giglio, N. V. Pavel and A. Zanobit, J. Phys. Chem., 1987, 91, 356-362.

41. F. Palazzesi, M. Calvaresi and F. Zerbetto, Soft Matter, 2011, 7, 9148-9156.

42. K. Matsuoka and Y. Moroi, Biochim. Biophys. Acta, 2002, 1580, 189-199.

43. T. S. Wiedmann and L. Kamel, J. Pharm. Sci., 2002, 91, 1743-1764.

44. M. Usman, M. A. Rashid, A. Mansha and M. Siddiq, Thermochim. Acta, 2013, 573, 18-24.

45. M. Usman and M. Siddiq, Spectrochim. Acta A: Mol. Biomol. Spectrosc., 2013, 113, 182-190.

46. M. Rahman, M. A. Khan, M. A. Rubb and Md. A. Hoque, J. Mol. Liq., 2016, 223, 716-724. 